\title{
Understanding the American Families Plan
}

Michelle Winokur, DrPH, and the AfPA Governmental Affairs

Team, Alliance for Patient Access (AfPA)

The Alliance for Patient Access (allianceforpatientaccess.org), founded in 2006, is a national network of physicians dedicated to ensuring patient access to approved therapies and appropriate clinical care. AfPA accomplishes this mission by recruiting, training and mobilizing policy-minded physicians to be effective advocates for patient access. AfPA is organized as a non-profit 501(c)(4) corporation and headed by an independent board of directors. Its physician leadership is supported by policy advocacy management and public affairs consultants. In 2012, AfPA established the Institute for Patient Access (IfPA), a related 501(c) (3) non-profit corporation. In keeping with its mission to promote a better understanding of the benefits of the physician-patient relationship in the provision of quality healthcare, IfPA sponsors policy research and educational programming.

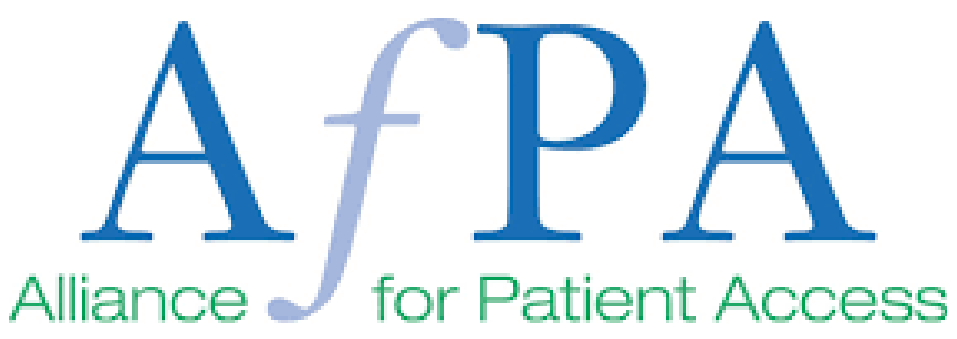

"By now, most everyone has heard of President Biden's American Families Plan, the \$1.8 trillion proposal presented to Congress on April 28. (1) While the details are not all final, the proposal is poised to impact families with babies and young children. Here is a look at a few key components."

By now, most everyone has heard of President Biden's American Families Plan, the $\$ 1.8$ trillion proposal presented to Congress on April 28. (1) While the details are not all final, the proposal is poised to impact families with babies and young children. Here is a look at a few key components.

\section{National Comprehensive Paid Family and Medical Leave}

President Biden described the country as "on the move again," which includes being back at work. That requires supporting those who may need to step back from work to care for themselves or a family member.

\section{"President Biden proposed an} investment of $\$ 225$ billion for a partial wage replacement of up to $\$ 4,000$ a month for workers who take leave to bond with a new child, care for a seriously ill loved one or heal from their own illness, among other reasons."

President Biden proposed an investment of $\$ 225$ billion for a partial wage replacement of up to $\$ 4,000$ a month for workers who take leave to bond with a new child, care for a seriously ill loved one or heal from their own illness, among other reasons. As outlined, his plan would take a decade to implement fully, building to 12 weeks of paid parental, family, and personal illness leave in the final year.

The proposed changes would "bring the American system in line with competitor nations that offer paid leave programs."

\section{Expanded Nutrition Programs}

The American Families Plan includes a $\$ 45$ billion investment in reducing childhood hunger and food insecurity, disproportionately affecting low-income families and communities of color. One component of President Biden's plan would make permanent the summer EBT program. The existing pilot provides money for food to the families of the 29 million children who receive free and reduced-price meals at school during the academic year.

The funds for this and other newly proposed nutrition plans appear to be separate from those the White House announced in mid-April as part of its efforts to curb Black maternal mortality. That proposal included $\$ 6$ billion to expand the Special Supplemental Nutrition Program for Women, Infants, and Children. (2)

When taken together, the actions demonstrate that the BidenHarris administration aims to tackle nutrition access on multiple fronts.

\section{Extend Tax Credit Programs}

The American Families Plan also builds upon the groundwork laid by the Trump administration and the stimulus package that was passed in March by expanding the child care tax credit. Families with children younger than 13 could receive up to $\$ 4,000$ for child care for one child or $\$ 8,000$ for multiple children.

It also extends the existing child tax credit through 2025 and makes it "fully refundable." This extension means low-income households that do not earn enough to claim it would still receive the benefit - $\$ 3,600$ for children under age six and $\$ 3,000$ a year for children ages 6 to 17, for most families. 


\section{Paying for It}

The power to fund the president's American Families Plan lies with Congress. The White House has suggested several ways to generate the needed revenue, including increasing capital gains taxes and raising the income tax rate for high-income individuals and businesses.

Now members of Congress will determine the next steps. While Republicans are balking at new taxes, some Democrats say the plan does not go far enough. These concerns paint an uncertain future for the plan. For now, the Biden-Harris administration, like all Americans, will have to wait and see what happens.

\section{References:}

1. The United States Government. (2021, April 28).

Fact Sheet: The American Families Plan. The

White House. https://www. whitehouse.gov/briefingroom/statements-releases/2021/04/28/fact-sheetthe-american-families-plan/.

2. The United States Government. (2021, April 13). Fact Sheet: Biden-Harris Administration Announces Initial Actions to Address the Black Maternal Health Crisis. The White House. https:// www.whitehouse.gov/briefing-room/statementsreleases/2021/04/13/fact-sheet-biden-harris-administration-announces-initial-actions-to-addressthe-black-maternal-health-crisisl.

Michelle Winokur, DrPH, is the Policy Communications Director for the Alliance for Patient Access.

Disclosures: The author has no disclosures

\section{NT}
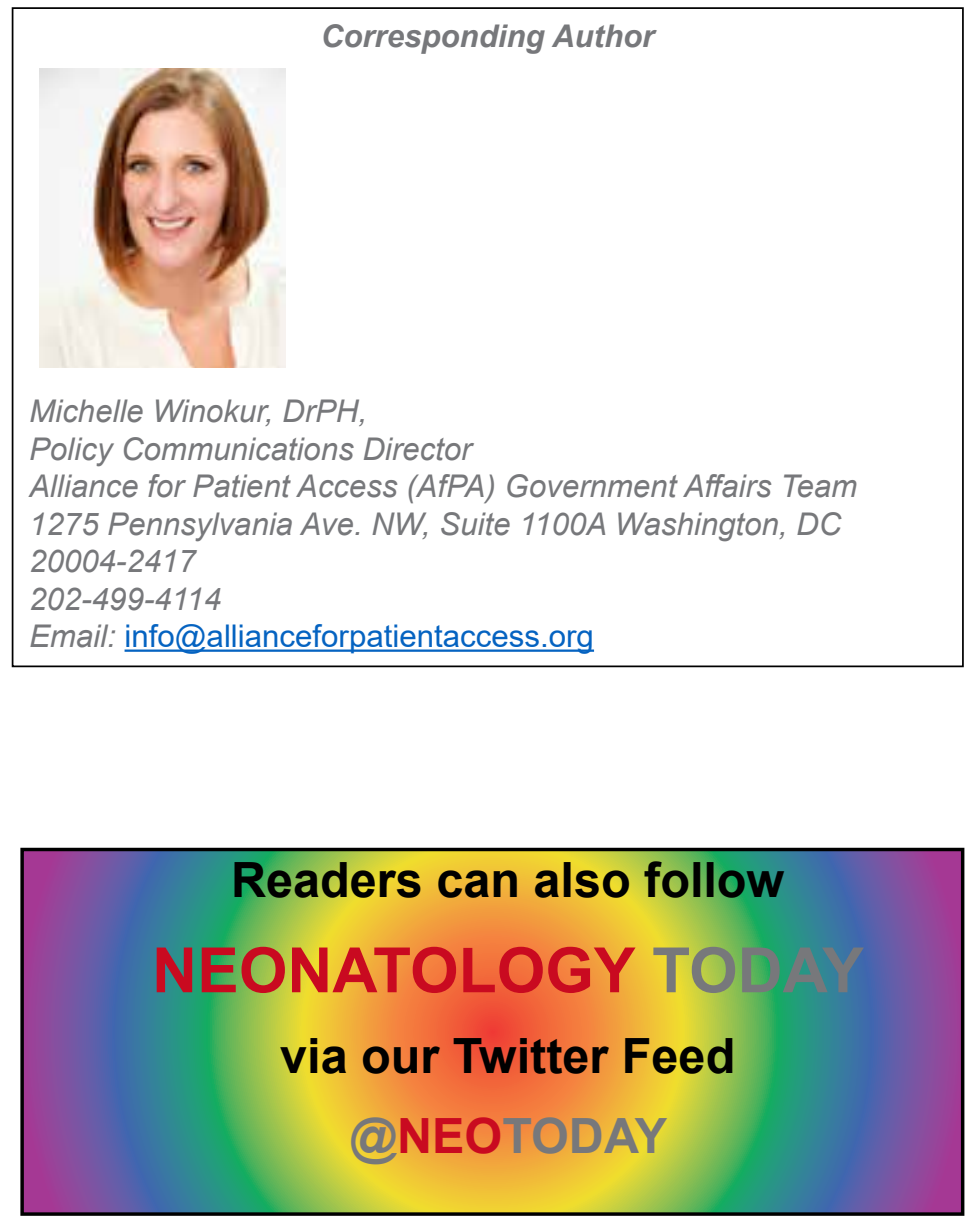

20004-2417

Email: info@allianceforpatientaccess.org

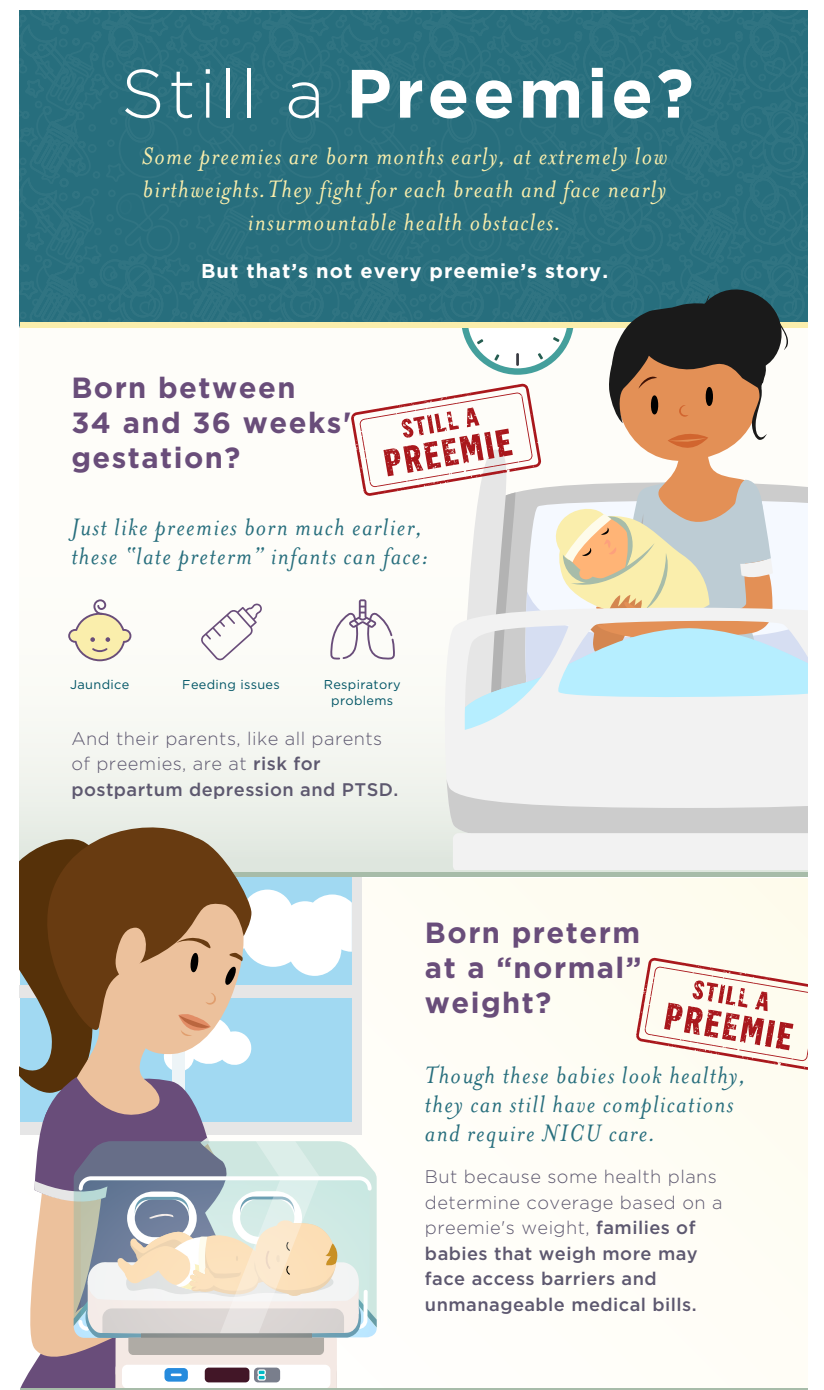

Born preterm but not admitted to the NICU?

Even if preterm babies

don't require NICU care,

they can still face health challenges.

Those challenges can extend through childhood, adolescence and even into adulthood.
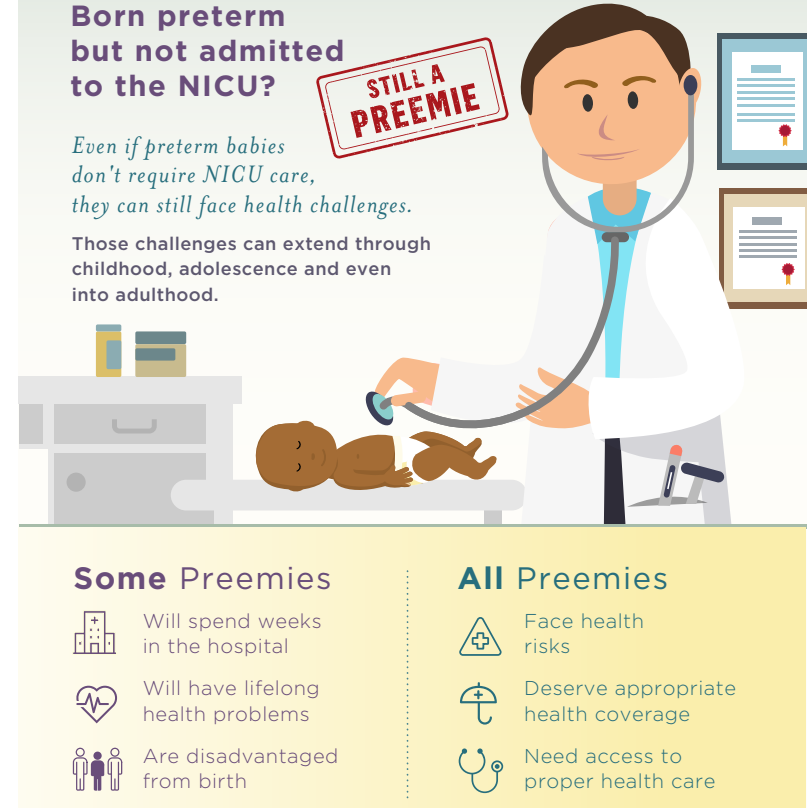